\title{
Ophthalmic alterations in horses with leptospirosis by serovar Icterohaemorrhagiae in Rio de Janeiro, Brazil ${ }^{1}$
}

\author{
Juliana Braga², Camila Hamond², Gabriel Martins², Renata Neves Abreu² \\ and Walter Lilenbaum²*
}

\begin{abstract}
Braga J., Hamond C., Martins G., Abreu R.N. \& Lilenbaum W. 2011. Ophthalmic alterations in horses with leptospirosis by serovar Icterohaemorrhagiae in Rio de Janeiro, Brazil. Pesquisa Veterinária Brasileira 31(2):147-150. Departamento de Microbiologia e Parasitologia, Universidade Federal Fluminense, Rua Hernani Mello 101, sala 309, Niterói, RJ 24210-130, Brazil. E-mail: mipwalt@ vm.uff.br

The objective of the study was to determine the association between clinical ophthalmic alterations and seroreactivity to leptospirosis by serovar Icterohaemorrhagiae in horses in Rio de Janeiro, Brazil. A total of 199 horses were studied. A microscopic agglutination test (MAT) was used to detect specific anti-Leptospira antibodies in blood serum. A total of $107(53.8 \%)$ horses were seroreactive (titres $\geq 200)$; 54 had high $(\geq 800)$ titres, of which 44 were against serovar Icterohaemorrhagiae. Forty-two out of these 44, plus 40 seronegative horses (titers $\leq 100$ ) were given detailed ophthalmic examinations. Epiphora, ocular congestion, blepharospasm, photophobia, and peripapillary focal depigmentation were the most frequent alterations in seroreactive horses. Most ocular alterations were significantly more frequent in seroreactive horses. Horses seroreactive for leptospirosis (serovar Icterohaemorrhagiae) had a significantly higher prevalence of ophthalmic alterations than seronegative horses, providing additional evidence for an association between leptospirosis and equine uveitis.
\end{abstract}

INDEX TERMS: Equine uveitis, leptospirosis, ocular disease, eye, horse.

RESUMO.- [Alterações oftálmicas em cavalos com leptospirose por serovar Icterohaemorrhagiae no Rio de Janeiro.] O objetivo do estudo foi determinar a associação entre as alterações clínicas oftalmológicas e sororeatividade a leptospirose por serovar Icterohaemorrhagiae em cavalos no Rio de Janeiro. Um total de 199 animais foi estudado. O Teste da Aglutinação Microscópica foi utilizado para detectar anticorpos específicos anti-Leptospira no soro dos animais. Um total de $107(53,8 \%)$ dos cavalos foram sororeativos (títulos >200); 54 tinham títulos elevados (>800), dos quais 44 foram reativos contra o serovar Icterohaemorrhagiae. Quarenta e dois dentre estes 44 , mais 40 cavalos soronegativos (títulos $<100$ ) foram submetidos ao exame oftalmológico. Epífora, congestão ocular, blefarospasmo, fotofobia, e despigmentação focal peripapilar foram as alterações mais frequentes nos animais sororeativos. Muitas alterações ocu-

\footnotetext{
${ }^{1}$ Received on August 27, 2010.

Accepted for publication on September 15, 2010.

2 Departamento de Microbiologia e Parasitologia, Universidade Federal Fluminense (UFF), Rua Hernani Mello 101, sala 309, Niterói, RJ 24210-130, Brazil. * Corresponding author: mipwalt@ vm.uff.br
}

lares foram significativamente mais frequentes em cavalos sororeativos. Animais sororeativos para leptospirose (serovar Icterohaemorrhagiae) tinham uma prevalência significativamente elevada de alterações oftálmicas em relação aos animais soronegativos, fornecendo evidências adicionais para associação entre leptospirose e uveíte equina.

TERMOS DE INDEXAÇÃO: Uveíte equina, leptospirose, doença ocular, olho, cavalo.

\section{INTRODUCTION}

Leptospirosis is a widespread zoonotic disease caused by spirochetes from the genus Leptospira. In horses, it has a wide spectrum of effects, ranging from no apparent clinical signs to death (Gilger 2005, Pinna et al. 2007). Infection with these organisms commonly results in impaired reproductive function in mares, as well as uveitis (Lilenbaum 1998, Faine et al. 2000, Hartskeerl et al. 2004, Gilger 2005, Pearce et al. 2007).

Equine recurrent uveitis (ERU), also known as moon blindness or periodic ophthalmia, is the most common cause of blindness in horses worldwide (Faber et al. 2000, Pearce et 
al. 2007). It is characterized by recurring episodes of intense intraocular inflammation in one or both eyes (Brandes et al. 2007). Clinical signs of ERU include miosis, blepharospasm, photophobia, aqueous flare, iritis, intraocular inflammatory precipitates (Sandmeyer et al. 2007). Chronically, synechia, cataract formation, atrophy of the corpora nigra, chorioretinitis, altered iris color, and ultimately blindness may be present (Dwyer et al. 1995). Although noninfectious (e.g. trauma) and infectious (bacterial, viral, protozoal, or parasitic) causes of ERU have all been postulated, its definitive etiology remains uncertain. Regardless, there are some reports of associations between ERU and leptospiral seroreactivity (Sillerud et al. 1987, Alexander \& Keller 1990, Dwyer et al. 1995, Hartskeerl et al. 2004, Frellstedt 2009). Furthermore, some horses infected with Leptospira developed clinical uveitis 1 to 2 years after infection (Williams et al. 1971), and ERU was 13.2 times more likely in seroreactive than seronegative horses (Paglia et al. 2006).

In Rio de Janeiro, Brazil, leptospirosis is endemic, and many animals of the Jockey Club are infected, since the region is subjected to flooding in the summertime. Previous reports have shown that Icterohaemorrhagiae is the predominant serovar in equine leptospirosis in Brazil (Lilenbaum 1998) as well as in other tropical areas (Faine et al. 2000). Although immunological testing of aqueous humor ( $\mathrm{AH}$ ) have demonstrated specific antibodies against serovars Grippotyphosa and Pomona in Europe and in the USA (Faine et al. 2000, Wollanke et al. 2001), there is a lack of studies conducted in topical areas where Icterohaemorrhagiae, a very aggressive and virulent strain (Faine et al. 2000), is the predominant Leptospira serovar.

The objective of the present study was to determine the association between clinical ophthalmic alterations and seroreactivity to leptospirosis by serovar Icterohemorrhagiae in horses in Rio de Janeiro, Brazil.

\section{MATERIALS AND METHODS}

Animals. A total of 199 Thoroughbred horses of both sexes, from 4 to 8 years of age, and not vaccinated against leptospirosis, living in a regular basis at the Rio de Janeiro Jockey Club, were studied. The animals had regular veterinary assistance including worming and vaccination against influenza, tetanus, rabies, encephalomyelitis and rhinopneumonitis, but not leptospirosis. The animals were kept in an area with constant flooding mainly during summertime and a rodent control program was not employed.

Samples. Blood samples were collected, by venipuncture of the vena jugularis, into Vacutainer ${ }^{\circledR}$ tubes, and allowed to clot for 4 hours at room temperature. Thereafter, samples were centrifuged (1000 $\mathrm{xg}$ for $10 \mathrm{~min}$ ) and serum was removed and stored at $-20^{\circ} \mathrm{C}$ and then all were thawed (room temperature for $1 \mathrm{~h}$ ) in a single batch immediately prior to serology.

Serology. Serum samples were tested for specific anti-Leptospira antibodies with microscopic agglutination tests (MAT) for 21 serovars (representing 16 serogroups) of Leptospira sp. grown in Ellinghausen liquid medium (EMJH), according to Faine et al. (2000). For all samples with agglutinating activity at 1:50 dilution, titres were better characterized by preparing further two-fold serial dilutions. Since the study was conducted in a tropical area, where leptospirosis is endemic (Lilenbaum 1998), only titres $>200$ were considered reactive; the antigen with the highest titre was considered the infective serovar.

Ophthalmologic examination. All horses with high seroreactive titres $(>800)$ against Icterohaemorrhagiae were selected to be observed by the same observer and designated to be given a detailed ophthalmic examination. Additionally, a group of 40 seronegative horses (titers $\leq 100$ ) of the same age and sex and living in the same conditions of the seroreactive animals, were randomly chosen to serve as a control group. First, superficial ocular structures were studied using a transilluminator and slit-lamp to examination of frontal structures. Next, binocular indirect ophthalmoscopy was conducted using an Eyetec ophthalmoscope (Heine Instruments, Kitchener, ON, Canada), with the aid of a handheld lens ( $20 \mathrm{dpt}$ ) to magnify and observe a larger area of the ocular fundus. To examine specific areas of interest, direct ophthalmoscopy was conducted using a panoptic ophthalmoscope (Welch Allyn, Skaneateles Falls, NY, USA). The prevalence of the following ocular changes was recorded: epiphora, blepharospasm, photophobia, ocular congestion, anterior or posterior synechia, cataract, corneal edema, iris color change, iris atrophy, peripapillary alar depigmentation, and peripapillary focal depigmentation.

Statistics. For each ophthalmic alteration, its prevalence in horses seronegative and seroreactive to leptospirosis was compared by a chi-square test ( $p<0.05$ was considered significant).

\section{RESULTS}

Overall, 107 of 199 (53.8\%) horses were seroreactive (titres $>200)$, with high titres $(>800)$ in $54(50.4 \%$ of seroreactive horses). Although low titres were observed for serovars Hardjo $(8.5 \%)$ and Hebdomadis (7.5\%), Icterohaemorrhagiae was by far the most frequent serovar $(74.8 \% ; p<0.05)$, and 44 out of the 54 horses that were seroreactive to Icterohaemor-

Table 1. Prevalence of ophthalmic alterations in 38 seroreactive horses (with titres $\geq 800$ ) for leptospirosis (serovar Icterohaemorrhagiae) and in $\mathbf{4 0}$ seronegative horses (titers $\leq 100$ ) in Rio de Janeiro, Brazil

\begin{tabular}{|c|c|c|c|c|c|c|c|}
\hline \multirow[t]{2}{*}{ Alteration } & \multirow[t]{2}{*}{ resence } & \multicolumn{2}{|c|}{$\begin{array}{l}\text { Soro- } \\
\text { reactive }\end{array}$} & \multicolumn{2}{|c|}{$\begin{array}{c}\text { Soro- } \\
\text { negative }\end{array}$} & \multicolumn{2}{|c|}{ Total } \\
\hline & & No. & $\%$ & No. & $\%$ & No. & $\%$ \\
\hline \multirow[t]{2}{*}{ Epiphora* } & $Y \epsilon$ & 25 & 65.8 & 5 & 12.5 & 30 & 38.5 \\
\hline & & 1 & 34.2 & 35 & 87.5 & 48 & 61.5 \\
\hline \multirow[t]{2}{*}{ Ocular congestion* } & * Yes & 22 & 45.8 & 5 & 12.5 & 27 & 34.6 \\
\hline & $\mathrm{N}$ & 2 & 54.2 & 35 & 87.5 & 51 & 65.4 \\
\hline \multirow[t]{2}{*}{ Blepharospasm* } & Yes & 18 & 40.9 & 0 & 0.0 & 18 & 23.1 \\
\hline & $N$ & 2 & 59.1 & 40 & 100.0 & 50 & 76.9 \\
\hline \multirow[t]{2}{*}{ Photophobia* } & Yes & 18 & 40.9 & 0 & 0.0 & 18 & 23.1 \\
\hline & No & 2 & 59. & 40 & 100.0 & 50 & 76.9 \\
\hline \multirow{2}{*}{$\begin{array}{l}\text { Peripapillary focal } \\
\text { depigmentation* }\end{array}$} & Yes & 1 & 38.1 & 3 & 7.5 & 19 & 24.4 \\
\hline & No & 2 & 61. & 37 & 92.5 & 49 & 73.6 \\
\hline \multirow[t]{2}{*}{ Iris ocular changes* } & $s^{*}$ Yes & 10 & 26.3 & 0 & 0.0 & 10 & 12.8 \\
\hline & No & 28 & 73.7 & 40 & 100.0 & 68 & 87.2 \\
\hline \multirow{2}{*}{$\begin{array}{l}\text { Peripapillary alar* } \\
\text { depigmentation* }\end{array}$} & Yes & 7 & 18.4 & 0 & 0.0 & 7 & 9.0 \\
\hline & No & 31 & 81.6 & 40 & 100.0 & 71 & 91.0 \\
\hline \multirow[t]{2}{*}{ Iris atrophy** } & Yes & 2 & 5.3 & 0 & 0.0 & 2 & 2.6 \\
\hline & No & 36 & 94.7 & 40 & 100.0 & 76 & 97.4 \\
\hline \multirow[t]{2}{*}{ Cataract $^{* *}$} & Yes & 1 & 2.6 & 1 & 2.5 & 2 & 2.6 \\
\hline & No & 37 & 97.4 & 39 & 97.5 & 76 & 97.4 \\
\hline
\end{tabular}

Difference in prevalence between seropositive and seronegative horses: ${ }^{*}(p<0.01),{ }^{* *}(p<0.05)$. 
rhagiae presented high titres $(>800)$. From those, ophthalmic examination was conducted in 42 plus a control group composed by 40 seronegative horses $(<100)$, totaling 82 horses. Of these, $38(90.5 \%)$ had at least one ocular alteration. Epiphora (65.8\%), ocular congestion (45.8\%), blepharospasm (40.9\%), photophobia (38.1\%), and peripapillary focal depigmentation (18.4\%) were the most prevalent alterations among seroreactive horses. Regarding the 40 seronegative horses that comprised the control group, 32 $(80 \%)$ had no ocular alterations, whereas epiphora, ocular congestion and peripapillary focal depigmentation were detected in five, five, and three horses, respectively. Nearly all ocular alterations were significantly more prevalent in seroreactive animals (Table 1). Although some animals presented systemic signs suggestive to leptospirosis, e.g. jaundice (four horses) and pulmonary hemorrhages (12 horses), those data were not considered since they are not the object of this study.

\section{DISCUSSION}

The high prevalence of seroreactive horses in the present study was not surprising, since leptospirosis, primarily due to serovar Icterohaemorrhagiae, is an important and common disease in horses in many tropical areas, including Rio de Janeiro (Lilenbaum 1998, Pinna et al. 2007). Additionally, the horses were kept in an area with constant flooding and no rodent control program was employed.

That $90.5 \%$ of seroreactive horses subjected to a detailed ophthalmic examination had at least one ocular alteration was noteworthy. In the present study, the association of seroreactivity to leptospirosis (high titres) and the high prevalence of ophthalmic alterations (significantly greater than in seronegative horses maintained in the same environment), contributed to strengthening the association between leptospirosis and ocular abnormalities in the horse.

In the USA and Europe, more than $50 \%$ of the cases of ERU were attributed to leptospirosis (Deeg et al. 2001), and specific antibodies and the agent were frequently detected (by culture and PCR) in tears and aqueous humor (Lucchesi et al. 2002, Pearce et al. 2007, Braga et al. 2010). The equine cornea and lens equine share antigenic properties with leptospires, and those shared antigens may cause the anti-Leptospira antibodies to bind to the cornea, leading to activation of the complement system and injury to the tissue (Pearce et al. 2007).

The specific clinical signs of ERU vary in accordance with the intensity and duration of disease (Frellstedt 2009). That these factors were not controlled in the present study undoubtedly contributed to the variation in clinical signs. Since only horses with high titres were studied, we inferred that most were in the acute phase of the infection. In that regard, the most prevalent alterations, namely epiphora $(p<0.05)$, blepharospasm $(p<0.05)$, and photophobia $(p<0.05)$, are classic indicators of an acute inflammatory reaction of the eye (Deeg et al. 2001, Lucchesi et al. 2002). Furthermore, the high prevalence of ocular congestion
(57.9\%), in seroreactive animals, although unspecific, was consistent with highly vascular uveal tissue and congestion as a cardinal sign of inflammation (Gilger 2005). In addition, it is noteworthy that a primary lesion of leptospirosis includes damage to the endothelial lining of small blood vessels (Frellstedt 2009). Other indications of uveitis in the posterior segment were also significantly more prevalent in seroreactive horses, including peripapillary focal or alar depigmentation, that resulted in chorioretinal scarring in the nontapetal area of the retina, known as "bullet hole" and "butterfly" lesions respectively (Gilger 2005, Paglia et al. 2006).

\section{CONCLUSION}

Horses seroreactive for leptospirosis (serovar Icterohaemorrhagiae) had a significantly higher prevalence of ophthalmic alterations (primarily epiphora, ocular congestion, blepharospasm, photophobia, and peripapillary focal depigmentation) than seronegative horses, providing additional evidence for an association between leptospirosis and ocular problems.

Acknowledgments.- The authors are thankful for critical reviews and suggestions by Prof. John Kastelic, Prof. Daniel Lessa, Dr. Guilherme Souza, and Prof. Felipe Wouke. WL is a CNPq fellow and this study was supported by FAPERJ and CNPq.

\section{REFERENCES}

Alexander C.S. \& Keller H. 1990. Etiology and occurrence of periodic eye inflammation of horses in the area of Berlin. Tierärztl. Praxis 18:623.

Braga J., Hamond C., Martins G. \& Lilenbaum W. 2010. Detection of anti-Leptospira antibodies in aqueous humor of horses with naturally occurring uveitis. Online J. Vet. Res. 14:212-217.

Brandes K., Wollanke B., Niedermaier G., Brem S. \& Gerhards H. 2007. Recurrent uveitis in horses: vitreal examinations with ultrastructural detection of leptospires. J. Vet. Med. A, Physiol. Pathol. Clin. Med. 54:270-275.

Deeg C.A., Kaspers B., Gerhards H., Thurau S.R., Wollanke B. \& Wildner G. 2001. Immune responses to retinal autoantigens and peptides in Equine Recurrent Uveitis. Invest. Ophthalmol. Vis. Sci. 42:393-398.

Dwyer A.E., Crockett R.S. \& Kalsow C.M. 1995. Association of leptospiral seroreactivity and breed with uveitis and blindness in horses: 372 cases (1986-1993). J. Am. Vet. Med. Assoc. 207:1327-31.

Faber N.A., Crawford M. \& Lefebvre R.B. 2000. Detection of Leptospira spp. in the aqueous humor of horses with naturally acquired recurrent uveitis. J. Clin. Microbiol. 38:2731-2733.

Faine S., Adler B., Bolin C. \& Perolat P. 2000. Leptospira and Leptospirosis. $2^{\text {nd }}$ ed. MedScience, Melbourne. 272p.

Frellstedt L. 2009. Equine recurrent uveitis: A clinical manifestation of leptospirosis. Equine Vet. J. 10:546-552.

Gilger B.C. 2005. Equine Ophthalmology. Elsevier Saunders, Philadelphia, p.285-321.

Hartskeerl R.A., Goris M.G., Brem S., Meyer P., Kopp H., Gerhards H. \& Wollanke B. 2004. Classification of Leptospira from the eyes of horses suffering from recurrent uveitis. J. Vet. Med. B 3:110-115.

Lilenbaum W. 1998. Leptospirosis on animal reproduction: IV. Serological findings in mares from six farms in Rio de Janeiro, Brazil (1993-1996). Braz. J. Vet. Res. Anim. Sci. 35:61-63.

Lucchesi P.M.A., Parma A.E. \& Arroyo G.H. 2002. Serotype distribution 
of a DNA sequence involved in the antigenic relationship between Leptospira and equine cornea. BMC Microbiol. 12:1-5.

Paglia D.T., Miller P.E. \& Dubielzig R.R. 2006. Wardrop and equine recurrent uveitis. Invest. Ophthalmol. Vis. Sci. 47:652-656.

Pearce J.W., Galle L.E., Kleiboeker S.B., Turk J.R., Schommer S.K., Dubielizig R.R., Mitchell W.J., Moore C.P. \& Giuliano E.A. 2007. Detection of Leptospira interrogans DNA and antigen in fixed equine eyes affected with end-stage equine recurrent uveitis. J. Vet. Diagn. Invest. 19:686-690.

Pinna M.H., Varges R., Abreu R. \& Lilenbaum W. 2007. Outbreak of equine leptospirosis by $S$. bratislava. Online J. Vet. Res. 3:1-4.

Sandmeyer L.S., Grahn B.H. \& Breaux C.B. 2007. Diagnostic ophthal- mology. Anterior and posterior uveitis with inflammatory retinal detachment, most likely secondary to equine recurrent uveitis. Can. Vet. J. 48:97-98.

Sillerud C.L., Bey R.F. \& Ball M. 1987. Serologic correlation of suspected Leptospira interrogans serovar Pomona-induced uveitis in a group of horses. J. Am. Vet. Med. Assoc. 191:1576.

Williams R.D., Morter R.L., Freeman M.J. \& Lavignette A.M. 1971. Experimental chronic uveitis. Ophthalmic signs following equine leptospirosis. Invest. Ophthalmol. 10:948-954.

Wollanke B., Rohrbach B. \& Gerhards H. 2001. Serum and vitreous humor antibody titers in and isolation of Leptospira interrogans from horses with recurrent uveitis. J. Am. Vet. Med. Assoc. 219:795-800. 